\title{
Penggunaan Catalytic Converter dari Bahan Kuningan dengan Ketebalan 0,2 mm terhadap Emisi Gas Buang Kendaraan pada Motor 2 Tak
}

\author{
Imam Prasetyo ${ }^{1}$, Muhammad Fahrurrozi ${ }^{2}$ \\ ${ }^{1,2}$ Program Studi Teknik Mesin Universitas Muhammadiyah Pekajangan Pekalongan \\ Email : ${ }^{1}$ imamprasetyo27@gmail.com, ${ }^{2}$ luke.fahrurrozi26@gmail.com
}

\begin{abstract}
ABSTRAK
Dalam mengurangi sisa emisi gas buang motor yang berbahaya, salah satunya dengan meningkatkan kualitas bahan bakar dan teknologi kendaraan agar pembakaran menjadi lebih baik dan lebih optimal, kemudian cara kedua adalah mengolah gas buang melalui alat pengontrol emisi gas buang. Catalytic Converter adalah suatu alat yang dipasang pada saluran pembuangan gas kendaraan yang berfungsi untuk mereduksi emisi sisa hasil dari gas pembakaran bermotor. Tujuan penelitian ini untuk mengetahui bagaimana pengaruh dari penggunaan catalytic converter dari bahan kuningan dengan ketebalan 0,2 mm untuk mengurangi kadar gas $\mathrm{CO}$ dan $\mathrm{HC}$ pada kendaraan bermotor. Pengujian dilakukan dengan menggunakan alat gas analyzer untuk mengetahui nilai konsentrasi CO dan HC. Pengujian emisi gas buang dilakukan dalam dua tahap yaitu uji emisi gas buang dengan knalpot standar dan uji emisi gas buang dengan catalytic converter dengan variasi putaran mesin $1500 \mathrm{rpm}, 2000 \mathrm{rpm}, 2500 \mathrm{rpm}, 3000 \mathrm{rpm}, 3500 \mathrm{rpm}, 4000 \mathrm{rpm}$. Dari hasil penelitian didapat bahwa pengaruh penggunaan catalytic converter dari bahan kuningan dengan ketebalan $0,2 \mathrm{~mm}$ dengan model sirip mengalami penurunan kadar emisi gas buang paling efektif pada putaran mesin 1500 rpm yaitu nilai CO turun 1,82\% dari 3.96\% menjadi 2,14\% dan nilai HC turun 4.412 ppm dari 9.999 ppm turun ke 5.587 ppm.
\end{abstract}

Kata Kunci : Catalytic Converter, Kuningan, Emisi Gas Buang.

\section{ABSTRACT}

In reducing the remaining harmful exhaust emissions of motorcycles, one of them is by improving the quality of fuel and vehicle technology so that the combustion becomes better and more optimal, then the second way is to process exhaust gas through an exhaust emission controller. Catalytic Converter is a device that is installed in the exhaust channel of vehicle which has function to reduce the residual emissions from motorized combustion gases. The purpose of this study was to determine the effect of using a catalytic converter made of brass with a thickness of $0.2 \mathrm{~mm}$ to reduce levels of $\mathrm{CO}$ and $\mathrm{HC}$ in motorized vehicles. Tests were carried out by using a gas analyzer to determine the value of $\mathrm{CO}$ and HC concentrations. The exhaust emission test is carried out in two stages, the exhaust emission test with a standard exhaust and exhaust gas emission test with a catalytic converter with the variations of engine speed of $1500 \mathrm{rpm}, 2000 \mathrm{rpm}, 2500 \mathrm{rpm}, 3000 \mathrm{rpm}, 3500 \mathrm{rpm}, 4000 \mathrm{rpm}$. From the research results, it was found that the effect of using a catalytic converter made of brass with a thickness of $0.2 \mathrm{~mm}$ with a fin model the most effective decreased on exhaust emission levels was at $1500 \mathrm{rpm}$, the CO value decreased by $1.82 \%$ from $3.96 \%$ to $2.14 \%$. and HC value fell 4,412 ppm from 9,999 ppm down to 5,587 ppm.

Keywords: Catalytic Converter, Brass, Flue Gas Emissions.

\section{Pendahuluan}

Pengendalian emisi gas buang ditentukan oleh pemerintah melalui Peraturan Menteri Lingkungan Hidup No. 05 Tahun 2006, peraturan ini dikeluarkan oleh pemerintah guna upaya mengendalikan emisi gas buang yang dihasilkan dari kendaraan bermotor. Dalam mengurangi sisa emisi gas buang motor yang berbahaya, salah satunya dengan meningkatkan kualitas bahan bakar dan teknologi kendaraan agar pembakaran menjadi lebih baik dan lebih optimal, kemudian cara 
kedua adalah memberikan perlakuan terhadap gas buang dengan melalui alat pengendali emisi. Konverter katalitik (catalytic converter) salah satu teknologi yang sering diaplikasikan pada kendaraan bermotor. Logam mulia seperti paladium, platinum dan rodium adalah salah satu bahan dasar yang digunakan untuk membuat Konverter katalitik, karena bahan tersebut memiliki luas permukaan spesifik (specific surface area) yang besar. Namun kekurangan dari bahan tersebut memiliki harga yang mahal dan ketersediannya yang langka ditemui di alam [1].

Logam mulia menjadi alternatif dalam memecahkan masalah untuk menggantikan logam transisi yang bisa digunakan sebagai bahan alat catalytic converter. Karena harga logam transisi relatif murah. Logam transisi dipilih karena harganya relatif murah dari pada logam paladium, platinum dan rodium serta ketersediannya banyak di alam dan mudah didapat di pasaran. Logam transisi serta paduannya banyak diteliti guna mengurangi kadar emisi gas buang $\mathrm{CO}$ dan HC yang dipakai sebagai bahan dalam pembuatan catalytic conveter [2].

Pemasangan Catalytic Converter yang ditempatkan pada sistem saluran pembuangan dari sisa pembakaran merupakan salah satu teknologi yang diterapkan pada kendaraan bermotor guna mereduksi emisi gas buang seperti kadar gas CO dan HC. Maka pada pengujian ini, peneliti membuat alat rancang bangun modifikasi Catalytic Converter dari bahan kuningan sebagai katalisnya. Pembuatan Catalytic Converter dari bahan kuningan sebagai katalisnya bertujuan guna mengetahui seberapa besar pengaruh pemakaian katalis ini terhadap penurunan kadar emisi gas buang $\mathrm{CO}$ dan $\mathrm{HC}$ pada motor bensin dibandingkan dengan tidak memakai Catalytic Converter di tinjau dari berbagai variasi putaran mesin [3].

Karena bahan kuningan menurut Razali (2014) memiliki konduktivitas termal sebesar $110 \mathrm{~W} / \mathrm{m}^{\circ} \mathrm{K}$ dan titik lebur $915^{\circ} \mathrm{C}$ [4]. Semakin tinggi konduktivitas termal dan titik lebur atau melting point, maka semakin bagus pula bahan tersebut untuk digunakan sebagai catalytic atau katalis. Oleh karena itu pada penelitian ini menggunakan material kuningan pada catalytic converternya.

\section{Metodologi Penelitian}

\subsection{Catalytic Converter}

Suatu alat yang dipasang di kendaraan yang berfungsi untuk mengurangi kadar emisi gas buang pada kendaraan dengan jalan bahwa semakin merata sisa gas buang yang mengenai permukaan catalytic converter maka akan semakin besar emisi gas buang yang di reduksi [5].
Catalytic converter alat yang dirancang mengkonversi senyawa-senyawa beracun dalam gas buang menjadi zat-zat yang kurang beracun dan tidak beracun sudah digunakan oleh negara Amerika Serikat sejak tahun 1975 karena peraturan Envoronmental Protection Agency (EPA) yang semakin ketat dalam hal tentang gas buang kendaraan bermotor.

Harga catalytic converter yang mahal di pasaran disebabkan oleh katalis yang terbuat dari logam mulia dan sulit didapatkan seperti palladium, platinum dan rodium. Selain itu katalitik tersebut juga sangat rentan terhadap bahan bakar premium yang memiliki kadar timbal $(\mathrm{Pb})$ yang bisa merusak fungsi katalitik. Tidak semua kendaraan dilengkapi dengan teknologi tersebut, sehingga perlu adanya penelitian baru yang menghasilkan alat pereduksi emisi yang harganya terjangkau dan dengan bahan yang mudah didapatkan sehingga bisa diaplikasikan ke semua kendaraan bermotor. Material lain yang dapat digunakan sebagai mereduksi emisi gas buang adalah katalitik [6].

Tembaga $(\mathrm{Cu})$ dan seng $(\mathrm{Zn})$ merupakan salah satu logam paduan utama dari bahan kuningan. Sedangkan bahan paduan utama kuningan adalah tembaga $(\mathrm{Cu})$. Berat jenisnya 8,9 , titik lelehnya sampai $1083^{\circ} \mathrm{C}$, mempunyai daya hantar listrik dan panas yang baik dan tahan pengaruh udara lembab merupakan beberapa sifatsifat yang dimiliki oleh tembaga. Bahan paduan utama kedua adalah seng ( $\mathrm{Zn})$. Seng memiliki sifat-sifat antara lain: berat jenisnya $6,9-7,2$, titik cairnya $419^{\circ} \mathrm{C}$, titik didih $402^{\circ} \mathrm{C}$, dan tahan udara lembab. Seng biasa digunakan untuk melapis pelat besi agar tidak terjadi korosi [7].

Tabel 1. Properti Fisik Kuningan

\begin{tabular}{lc}
\hline \multicolumn{1}{c}{ Properti fisik } & Satuan \\
\hline Masa jenis & $8.4 \mathrm{~kg} / \mathrm{dm}^{3}$ \\
Titik lebur & $885-910^{0} \mathrm{C}$ \\
Modulus elastisitas & $102 \mathrm{Gpa}$ \\
Konduktifitas thermal & $109 \mathrm{~W} / \mathrm{M} . \mathrm{K}$ \\
Konduktifitas listrik & $13.9 \mathrm{~m} / \Omega$ \\
Resistivas listrik & $0.07 \Omega \mathrm{mm} / \mathrm{M}$ \\
Koefisien ekspansi linier & $21.1 \times 10^{-6} \mathrm{~K}^{-1}$ \\
$20^{0}$ sampai $300^{0} \mathrm{C}$ & \\
IAICS (International & \\
Annealed Copper & $24 \%$ \\
Standart) & \\
\hline
\end{tabular}

(Sumber: Laminage, 2008)

Menurut Razali (2014) dengan perpaduan jenis logam tembaga dan seng, maka kuningan $(70 \% \mathrm{Cu}$, 
$30 \% \mathrm{Zn}$ ) memungkinkan untuk digunakan sebagai catalytic pada saluran buang karena mempunyai konduktivitas termal sebesar $110 \mathrm{~W} / \mathrm{m}^{\circ} \mathrm{K}$ dan titik lebur $900^{\circ} \mathrm{C}$. Semakin tinggi konduktivitas termal dan titik lebur atau melting point, maka semakin bagus pula bahan tersebut untuk digunakan sebagai catalytic [4].

\subsection{Bahan Penelitian}

Dalam penelitian ini sebagai media uji memakai sebuah sepeda motor jenis 2 tak dengan kapasitas mesin $110 \mathrm{cc}$ dan objek bahan yang dipakai pada penelitian ini terdiri dari dua jenis, yaitu knalpot sepeda motor standar pabrik tanpa catalytic converter dan knalpot sepada motor modifikasi yang sudah di pasang catalytic converter. Untuk perancangan catalytic converter dilakukan berdasarkan ruang yang tersedia pada knalpot standar menggunakan pipa galvanis dengan diameter $40 \mathrm{~mm}$, panjang $100 \mathrm{~mm}$.

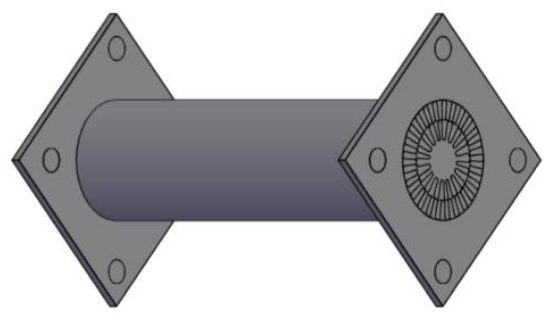

Gambar 1. Desain Catalytic Converter

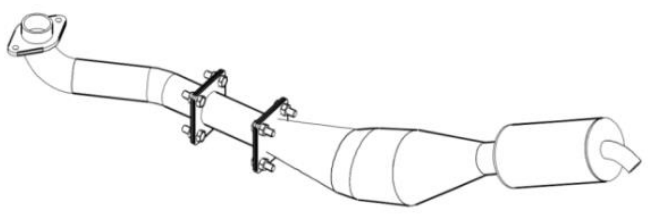

Gambar 2. Desain knalpot terpasang Catalytic Converter

Kemudian dalam pembuatan bahan Catalytic Converter ini terdiri dari dua bagian yaitu kontruksi bagian dalam dan kontruksi bagian luar. Untuk kontruksi bagian dalam berupa material substrat dan washcoat, lalu untuk konstruksi bagian luar berupa rumah katalis (chasing) dan penopang. Sedangkan material subtrat untuk konstruksi bagian dalam terbuat dari kuningan

( $\mathrm{CuZn}$ ) yang berbentuk potongan plat berukuran $12 \times 10 \mathrm{~cm}$ untuk pipa dinding luar dan ukuran $6 \times 10$ cm untuk pipa dinding dalam dengan ketebalan 0,2 mm. Kemudian untuk sirip-sirip bagian dalamnya menggunakan potongan plat dengan ukuran $40 \times 10 \mathrm{~cm}$ untuk sirip dinding luar dan ukuran $20 \times 10 \mathrm{~cm}$ untuk sirip pada dinding dalam.

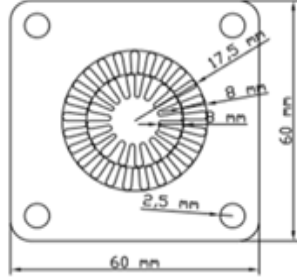

Tampak Depan

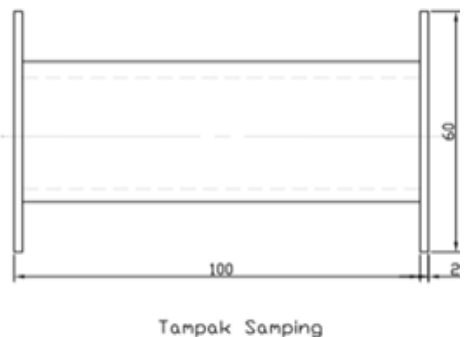

Gambar 3. Dimensi desain Catalytic Converter

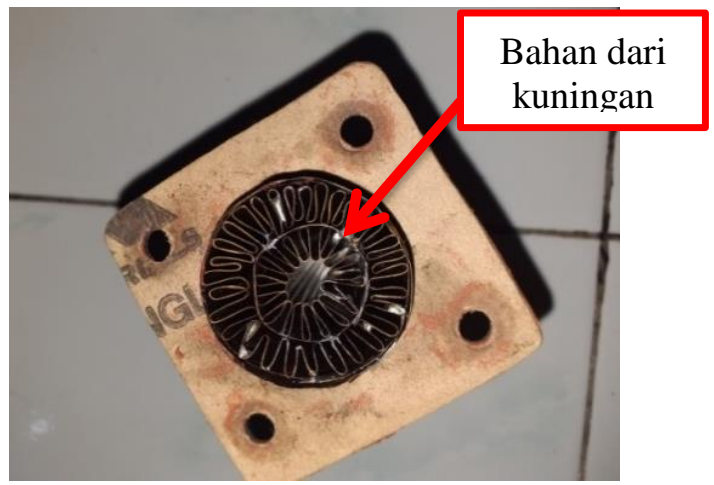

Gambar 4. Catalytic Converter sudah jadi

\subsection{Variabel Penelitian}

1. Variabel terikat pada penelitian ini adalah kadar hasil emisi gas buang berupa CO, HC

2. Variabel bebas pada penelitian ini yaitu:

a. Penggunaan Catalytic Converter dan tanpa menggunakan Catalytic Converter.

b. Variasi putaran mesin yaitu $1500 \mathrm{rpm}, 2000$ $\mathrm{rpm}, 2500 \mathrm{rpm}, 3000 \mathrm{rpm}, 3500 \mathrm{rpm}$ dan $4000 \mathrm{rpm}$

\subsection{Tahapan Pelaksanan Pengujian}

1. Menyiapkan 1 unit sepeda motor yang sudah di tune up guna mendapat data yang maksimal.

2. Persiapkan peralatan toolkit guna mendukung pengujian.

3. Melakukan pengecekan kondisi mesin.

4. Memulai mempersiapkan pengambilan data yang pertama, tanpa menggunakan Catalytic Converter.

5. Mengatur putaran mesin pada putaran yang sudah ditentukan yaitu (1500 rpm, $2000 \mathrm{rpm}$, $2500 \mathrm{rpm}, 3000 \mathrm{rpm}, 3500 \mathrm{rpm}, 4000 \mathrm{rpm}$ ).

6. Mencatat hasil angka yang keluar pada gas analyzer setiap pada putaran mesin yang sudah ditentukan.

7. Setelah pengambilan data selesai mematikan/mendinginkan mesin -/+ 30 menit.

8. Memulai mempersiapkan pengambilan data yang kedua yaitu dengan menggunakan Catalytic Converter. 
9. Pelaksanaan pengujian selanjutnya mengulangi langkah 5 sampai dengan langkah 7.

10. Setelah pengambilan data selesai, memasukan data yang diperoleh ke dalam tabel lalu membuat grafik dan menganalisanya.

\subsection{Teknik Analisa Data}

Penelitian ini menggunakan metode analisis data deskriptif, dimana data yang diperoleh dari hasil pengujian eksperimen dimasukkan ke dalam tabel, dan ditampilkan dalam bentuk grafik kemudian dibandingkan dan dianalisis kadar emisi gas buang kendaraan bermotor berupa gas $\mathrm{CO}$ dan $\mathrm{HC}$ dari hasil knalpot tanpa Catalityc Converter dan dengan knalpot menggunakan Catalityc Converter.

\section{Hasil dan Pembahasan}

Dari data hasil pengujian yang dilakukan saat penelitian akan disajikan dalam bentuk gambar grafik. Hal tersebut dilakukan untuk mempermudah analisis data, pembahasan dan penarikan kesimpulan.

\subsection{Hasil Pengujian Nilai CO Dengan Knalpot Standar Dan Knalpot Bercatalytic Converter}

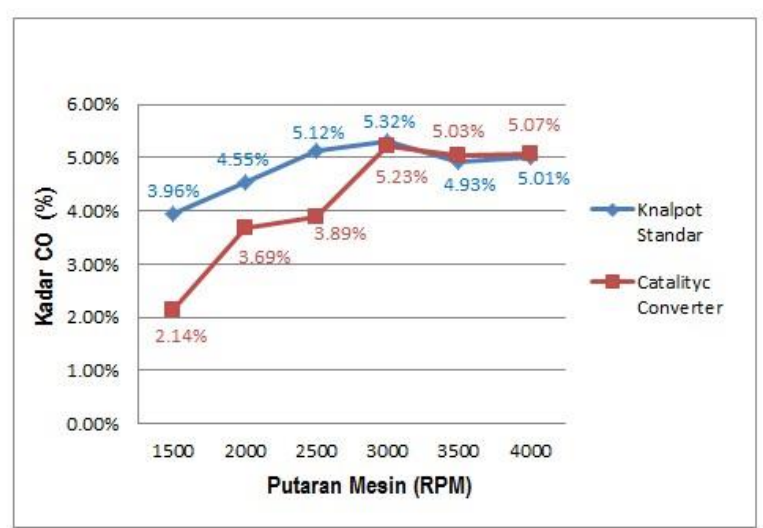

Gambar 5. Grafik perbandingan nilai CO dengan knalpot standar dan knalpot bercatalytic Converter

Berdasarkan data emisi pada gambar 5, putaran mesin minimum $1500 \mathrm{rpm}$, dan kecepatan maksimum dapat mencapai $4000 \mathrm{rpm}$. Diketahui bahwa pada putaran mesin $1500 \mathrm{rpm}$, terjadi penurunan konsentrasi emisi gas $\mathrm{CO}$ yang paling signifikan, yaitu nilai konsentrasi turun dari $3,96 \%$ sebesar $1,82 \%$ menjadi 2,14 . \%, pada putaran mesin $2000 \mathrm{rpm}$ dan putaran mesin $2500 \mathrm{rpm}$, penurunan nilai emisi gas CO sangat signifikan yaitu pada putaran mesin 2000 rpm nilai konsentrasi turun $0,89 \%$, dan pada putaran mesin 2500 rpm nilai konsentrasi turun $1,23 \%$ Namun, saat putaran mesin dari $3000 \mathrm{rpm}$ menjadi $4000 \mathrm{rpm}$ pada $2000 \mathrm{rpm}$, tingkat emisi tidak berkurang secara signifikan, bahkan pada putaran mesin $3500 \mathrm{rpm}$ dan $4000 \mathrm{rpm}$, nilai konsentrasinya justru sedikit meningkat. Hal ini dapat disebabkan oleh beberapa faktor, antara lain nilai AFR yang semakin besar yang mungkin terpengaruh, pengaruh katalis dan beban pada mesin uji (statis maupun non-statik), dan temperatur ruang bakar.

\subsection{Hasil Pengujian Nilai HC dengan Knalpot Standar dan Knalpot Bercatalytic Converter}

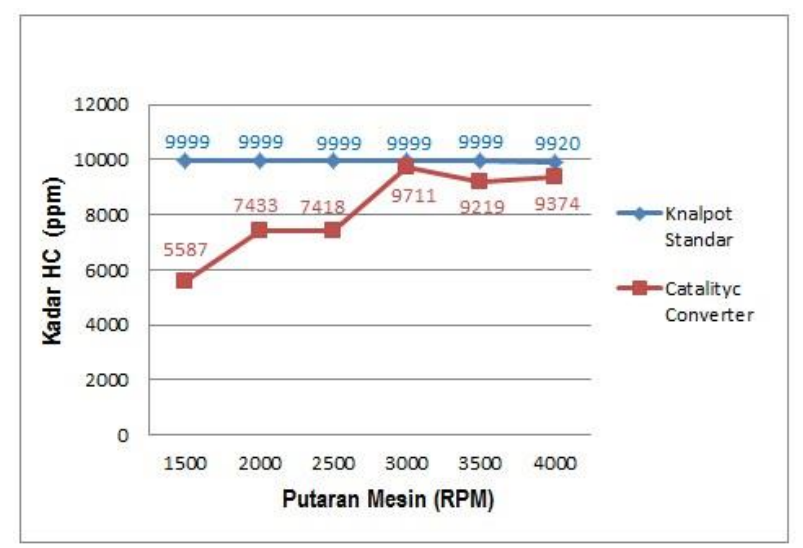

Gambar 6. Grafik perbandingan nilai HC dengan knalpot standar dan knalpot bercatalytic Converter

Melihat grafik diatas nilai emisi gas HC pada putaran mesin $1500 \mathrm{rpm}$ sampai $4000 \mathrm{rpm}$ nilai konsentrasi emisi gas $\mathrm{HC}$ dengan knalpot bercatalytic converter lebih rendah dibandingkan nilai emisi gas $\mathrm{HC}$ dengan knalpot standar atau bisa dikatakan bahwa nilai emisi gas $\mathrm{HC}$ tersebut bisa diturunkan dengan menggunakan knalpot bercatalytic converter tersebut.

Dilihat bahwa penurunan nilai konsentrasi gas $\mathrm{HC}$ paling signifikan terjadi pada putaran mesin $1500 \mathrm{rpm}$. Pada putaran mesin $1500 \mathrm{rpm}$ nilai konsentrasi gas HC turun 4412 ppm dari 9999 ppm turun ke 5587 ppm. Pada putaran $1500 \mathrm{rpm}$ sampai $4000 \mathrm{rpm}$ nilai konsentrasi gas $\mathrm{HC}$ terus mengalami penurunan namun pada putaran mesin $3000 \mathrm{rpm}$ sampai $4000 \mathrm{rpm}$ penurunan nilai konsentrasi dari gas $\mathrm{HC}$ tersebut tidak cukup signifikan. Dari hal ini bisa disimpulkan bahwa catalytic converter dengan bahan kuningan mampu menurunkan kadar emisi gas HC pada putaran mesin rendah.

\section{Penutup}

Berdasarkan hasil penelitian yang telah diselesaikan, dapat disimpulkan bahwa tingkat emisi $\mathrm{CO}$ dan $\mathrm{HC}$ terendah terjadi pada $1.500 \mathrm{rpm}$, tingkat emisi gas CO sebesar 3,96\%, dan kadar gas HC sebesar 9.999 ppm, tertinggi pada pengujian menggunakan knalpot standar. Tingkat emisi pada 4.000 rpm, kadar gas CO 5,01\%, dan kadar gas HC 9,920 ppm. Sedangkan pada gas buang dengan catalytic converter, tingkat emisi $\mathrm{CO}$ dan $\mathrm{HC}$ terendah terjadi pada 1.500 rpm, kadar gas CO 2,14\%, konsentrasi HC 9.999 ppm, 
dan tingkat emisi CO dan $\mathrm{HC}$ tertinggi pada $3.000 \mathrm{rpm}$. Jika kadar gas CO sebesar 5,23\% dan kadar gas HC 9.999 ppm, maka cara paling efektif untuk mengurangi emisi adalah dengan menggunakan catalytic converter kuningan setebal $0,2 \mathrm{~mm}$ dengan model sirip. Saat putaran mesin $1.500 \mathrm{rpm}$, nilai CO turun sebesar 1, dari $3,96 \%$ menjadi $82 \%$ dari $2,14 \%$, dan nilai HC turun dari 9.999 ppm menjadi 5.587 ppm, yang turun $4.412 \mathrm{ppm}$.

\section{Daftar Pustaka}

[1] R. B. Irawan and M. Subri, "Unjuk Kemampuan Catalytic Converter dengan Material Substrat Kuningan (Paduan CuZn) Untuk Mereduksi Gas Buang Motor Bensin," J. Litbang Univ. Muhammadiyah Semarang, pp. 48-55, 2005.

[2] A. Sanata, "Analisis Variasi Temperatur Logam Katalis Tembaga (CU) pada Catalytic Converter untuk Mereduksi Emisi Gas Karbonmonoksida (CO) dan Hidrokarbon (HC) Kendaraan Bermotor," J. ROTOR, vol. 5, no. 1, pp. 1-7, 2012.
[3] R. B. Irawan, "Efektifitas Katalis Material Subtrat Paduan CuZn (Kuningan) Dalam Meredusi Emisi Gas Karbon Monoksida Motor Bensin," Jurnal.unimas.ac.id, vol. 10, no. 2, pp. 29-40, 2010.

[4] A. Razali, H. Maksum, and Daswarman, "Perbandingan Gas Karbon Monosida (CO) dan Hidrokarbon (HC) yang Menggunakan Catalyst Kuningan dengan Catalyst Tembaga pada Motor Empat Langkah," Automot. Eng. Educ. J., vol. 2, no. 2, 2014.

[5] A. Mokhtar, "Catalityc Converter Jenis Katalis Plat Tembaga Berbentuk Sarang Lebah Untuk Mengurangi Emisi Kendaraan Bermotor," J. Gamma, vol. 10, no. 1, pp. 104-108, 2014.

[6] R. Manunggal and Warju, "Pengaruh Penggunaan Metallic Catalytic Converter Berbahan Tembaga Dan Aplikasi Teknologi Sass Terhadap Performa Sepeda Motor Honda New Mega Pro," J. Tek. Mesin Univ. Negeri Surabaya, vol. 1, no. 2, pp. 110-115, 2013.

[7] R. B. Irawan, "Efektifitas Pemasangan Catalytic Converter Kuningan Terhadap Penurunan Emisi Gas Carbon Monoksida Pada Kendaraan Motor Bensin," Traksi, vol. 9, no. 1, pp. 31-38, 2009. 